Article

\title{
Demystifying the Effects of Age at Marriage and Age at First Birth on Completed Family Size in Zambia
}

\author{
Nkuye Moyo ${ }^{1,2^{*}}$, Tina Nanyangwe-Moyo ${ }^{1}$, Xiaochun Qiao ${ }^{1^{*}}$, Jilei $\mathbf{W u}^{1}$ \\ 1 Institute of Population Research, Peking University, No. 5 yiheyuan Road, Beijing, China, 100871; \\ nkuye.moyo@pku.edu.cn; tina.nanyangwe@pku.edu.cn; qxc@pku.edu.cn; wujl@pku.edu.cn \\ 2 Department of Population Studies, University of Zambia, Great East Road Campus, Luaka, Zambia 10101; \\ nkuye.moyo@unza.zm \\ * Correspondence: nkuye.moyo@pku.edu.cn; Tel.: +86-150-1097-3070(NM); \\ qxc@pku.edu.cn; Tel.: +86-137-1812-7801 (XCQ)
}

\begin{abstract}
The link between age at marriage and first birth in explaining completed family size is not always direct, due to heterogeneity in circumstances, that compel individual women to marry or initiate childbearing at a particular age. We analyzed data for 1020 women aged 45-49 in 2014 of the 1965-1969 birth cohort from the 2013-14 ZDHS. We fitted a bivariate and multivariate multinomial logistic regression to establish the effect of mother's age at first marriage and at first birth on completed family size (CFS). Chi-square test of proportions measuring differences in proportions and relative risk ratios (RRR) with confident intervals at $95 \%$ are reported. Our results show that the average CFS was 6.7 (95\% CI: 6.5 - 6.9) among women completing their reproductive span in 2014 with mean age at first marriage and birth being 18.3 years (95\% CI: $18.0-18.5)$ and 18.9 years (95\% CI: 18.7 - 19.1) respectively. Women marrying at younger ages and having their first birth at younger ages were more likely (RRR: 0.262; 95\% CI:0.126-0.547 and RRR: 0.176; 95\% CI:0.068-0.497 respectively) to have higher CFS than their compatriots that initiated both marriage and childbearing at or after age 22. Having no education, being a rural resident and having a medium household wealth all increased the risk of having higher CFS. Women that marry before age 19 have a higher likelihood of having 6 or more children by the end of their reproductive period. The study concludes that apart from a woman's age at first marriage and first birth, a complex network of factors interact to determined CFS.
\end{abstract}

Key words Age at first marriage; age at first birth; completed family size; fertility

\section{Introduction}

Marriage assumes diverse denotations in different settings. Needless to say, every society has some form of a system which regulates the formation of a family and, one salient attribute of the act of family formation - called marriage(Bourgeois-pichat 2012), is that, it founds the basic unit of the social structure. Marriage is an institution where sexual intercourse is sanctioned and childbearing permitted (Bourgeois-pichat 2012; Central Statistical Office (CSO) et al. 2009; Central Statistical Office, Zambia, and Macro International Inc. 1997). Because of these two critical features, timing of entry into marriage, especially the age at which women first enter into a marital union becomes pivotal in measuring trends in fertility and patterns of CFS (Bourgeois-pichat 2012; Marini 1981) and may hold greater sway in efforts to control fertility. Regardless of the average age at first sexual intercourse or magnitude of sexual activity in a society, unmarried women in any age group are unlikely to produce as many live births as married women in corresponding age groups because of social, cultural and economic penalties against out-of-wedlock childbearing (Population Reports 1979). 
In Zambia, marriage begins early $-46 \%$ of women age $20-49$ marry by age 18 , and 66 percent by age 20 - and it is, by and large, universal as 78\% women and 90\% men aged $35-39$ are married(Central Statistical Office, Ministry of Health, Tropical diseases Research Centre 2009; Central Statistical Office et al. 2015). As early as women enter into a marital union so does the onset of childbearing. The 2013-14 ZDHS report indicates that 31\% of women in age cohort 20-24 in Zambia have had a first birth by exact age $18,50 \%$ by age 19 and, $61.3 \%$ by age 20(Central Statistical Office, Ministry of Health, University of Zambia Teaching Hospital, Tropical diseases Research Centre, University of Zambia 2015). Tendencies where childbearing is concentrated at younger ages exert substantial effect on fertility levels because of early marriage rates. Studies suggest that women who marry young are predisposed to three core demographic aspects which influence high fertility and larger CFSs: high frequency of sexual intercourse throughout their most fecund years; the early onset of childbearing and an extended period of exposure to the risk of conception and; a shortened interval before the next generation is born and begins childbearing(Population Reports 1979). The confluence of these factors plunges a population where women marry young into a cycle of high fertility.

As is the case for Zambia, aggregate fertility levels remain one of the highest in sub- Saharan Africa and globally (Central Statistical Office et al. 2015). Although fertility rates continue to exhibit falling trends, the pace is not robust enough. The Total Fertility Rate (TFR) progressively declined from 6.5 births per woman in 1992, 6.1 in 1996, 5.9 in 2010 and currently to 5.3 in 2014 (Central Statistical Office (CSO); Central Board of Health [Zambia]; , and ORC Macro 2003; Central Statistical Office (CSO) et al. 2009; Central Statistical Office et al. 2015; Central Statistical Office, Zambia, and Macro International Inc. 1997; University of Zambia (UNZA), Central Statistical Office (CSO), and Macro International Inc. 1993). There doesn't seem much hope for the short term since current rates of average completed family size still linger quite large, with women nearing the end of their reproductive years attaining a mean parity of 7 children (Central Statistical Office et al. 2015). This study is well aware that the link between age at marriage and first birth in explaining completed family size is not always direct, due to heterogeneity in circumstances, that compel individual women to marry or initiate childbearing at a particular age. The study was motivated by the fact that a precise understanding of relationships in marriage trends and dynamics thereof are important in identifying causes confounded by intricate country-specific socioeconomic factors. Therefore, the aim of the study was to investigate the independent and controlled effects of age at first entry into marriage and age at first birth on CFS for women aged 45-49.

\section{Literature Review}

Scholarly investigations of the relationship between timing of marriage and of first birth with completed family size are in abundance. Completed family size remains high in most African countries south of the Sahara due to a delayed onset of fertility transition (Ariho and Kabagenyi 2020; Bongaarts 2017). World-wide comparison show that Africa is yet to undergo or has just begun the fertility transition and though a noticeable decline in fertility in fertility has been achieved, African fertility is still the highest when related other regional blocks (Gerland, Biddlecom, and Kantorová 2017).

The pathways that describe sexual debut and its effect on fertility is somewhat different for young men and women. Studies have shown that education plays a crucial role in adolescents initiation to sexual activity. Most studies have shown that sexual activity, pregnancy and marriage are direct impediment to education attainment especially at secondary school level(Poulin 2007) and that dropping out of school is the main pathway to a myriad of reproductive events of sexual activity, pregnancy, or marriage (Caroline and Alex 2009; Clark, Kabiru, and Mathur 2010), that inevitably threatens completion secondary school prospects. Research indicates that more girls than boys that are sexually active drop out of (Lloyd 2010), and that sexual activity in more detriment to girls' than boys' education (Biddlecom A et al. 2007). This effect of early sexual activity and its eventual effect 
on school dropped out contributes to elevated premarital fertility among young people especially in countries that have improved ages at marriage. Another study found that girls that were already falling behind in studies at school had a higher probability of engaging in sexual activity than their counterparts who were doing well (Clark and Mathur 2012; Grant and Hallman 2008).

TFR in Zambia reduced from 6.1 in 1992, 5.9 in 2010, 5.3 in 2014 to 4.7 in 2018 (Central Statistical Office (CSO) [Zambia], Ministry of Health (MOH) [Zambia] 2014; Central Statistical Office Zambia (CSO) 2010; University of Zambia (UNZA), Central Statistical Office (CSO), and Macro International Inc. 1993; Zambia Statistical Agency (ZSA) et al. 2019). This latest TRF is higher than the current average for most of the African region (Bongaarts, Mensch, and Blanc 2017; Gilles Pison 2017). Though fertility has been declining in Africa, it remains high in comparison to other regions (Gilles Pison 2017). TFRs in the African region averaged 4.7 between 2010 and 2015 which is far above the global average of 2.5 though it is expected to drop by 2050, but will still be well above the rest of the world (United Nations Children's Fund (UNICEF) 2014). This high TFR fuels the next generation of mothers who will have fewer children than their preceding cohorts, but still more than the rest of the world. At this rate of fertility change, Africa will constitute $41 \%$ of the world's population and $40 \%$ of global under-five children by 2050 (Gilles Pison 2017; United Nations Children's Fund (UNICEF) 2014). Desire for family size is also driven by many factors such as education and wealth. A study conducted on East African countries found enormous heterogeneity in CFS (Muhoza, Broekhuis, and Hooimeijer 2014). It concluded that "Wealthy and highly educated people have fertility desires close to replacement level, regardless of religion, while poor, uneducated people, particularly those in Muslim communities, have virtually uncontrolled fertility" (Muhoza, Broekhuis, and Hooimeijer 2014). This somewhat confirms the assertion that higher fertility which is linked with early childbearing leads to reduced investments in the education and health of each child (Quisumbing and Maluccio 2003), which contributes to the intergenerational flow of poverty (Glick, Handy, and Sahn 2015).

The first time a woman enters marriage has huge implications on her health and that of her forthcoming offspring. Early systematic scholarly works by Lesthaeghe and colleagues (Lesthaeghe et al. 1989; Walle 1993) brought to light changes in age at marriage signifying an upward trend in most African countries. Many other scholars have undertaken extensive retrospective investigations that have added to the existing evidence of the increasing of age at first marriage for African females (Garenne 2004; Lloyd et al. 2005; Mensch, Grant, and Blanc 2006; Mensch, Singh, and Casterline 2006; Ortega 2014; Shapiro and Gebreselassie 2014; Westoff 1992). More recent findings by Hertrich confirm substantial change in first marriage patterns across the continent (Hertrich 2017). Work by Hertrich confirms an inverse relationship between age at first marriage and fertility; the higher the age at marriage the lower the fertility and vice versa (Hertrich 2017).

The time an individual starts parenthood is one of life's most challenging yet significant occurrences. A study based on DHS data of 43 countries found that the mean age at first birth was greater than the mean age at first marriage, which was also greater than the mean age at first sex for all regions (Bongaarts, Mensch, and Blanc 2017). Another study found that the effect of being married for 0-3 years was positive and statistically significant, and for being married 3-6years negative and statistically significant in as far as having a first birth is concerned in Madagascar implying that the probability of having a first birth is higher during the first years of marriage, but diminishes after the third year (Glick, Handy, and Sahn 2015). Several studies in the region posit that the mean age at first 
birth in sub Saharan Africa is about 21 with most of West and Middle African countries having age at first birth at or below 18 years while East and Southern African countries above 22 years (Bongaarts 2017; Bongaarts, Mensch, and Blanc 2017; Mensch, Grant, and Blanc 2006). The increasingly rising age at first birth in most African countries could be as a result of improved education outcomes for women which would translate in better health and reduced risks of maternal related morbidity and mortality and manageable fertility. Generally, reproductive indicators for women (age at sexual debut, first marriage and first birth) play a crucial role in determining the fertility levels and trends for any country.

\section{Methods and Data}

This study utilized data from the 2013-14 Zambia Demographic and Health Survey (ZDHS). ZDHS is a population-based cross-sectional study dedicated to investigating health status of the Zambia people. Survey data collected during the 2013-14 round of ZDHS covered behavioral, social and demographic indicators that included the fertility history of women, when they got married, and their age when they had their first birth. These variables were of great significance in measuring and understanding completed family size. The ZDHS obtained information on lifetime fertility of women that had completed childbearing and also analyzed the average number of children born to women in Zambia by the end of their reproductive cycle. The 2013-14 ZDHS investigation covered 722 clusters from which 18,052 households were identified. From the identified households, 16, 258 households were found occupied at the time of the investigation. The survey reported $98 \%(15$, $920 / 16,258$ ) household response rate from which 17,064 women aged 15-49 and 16, 209 men aged 1559 were identified and $96 \%(16,381 / 17,064)$ of these women as well as $91 \%(14,750 / 16,209)$ of the men successfully completed an interview. Urban areas exhibited a marginally lower individual response rate than rural areas. A detailed discussion on the methodology of the ZDHS is available elsewhere(Central Statistical Office (CSO) [Zambia], Ministry of Health (MOH) [Zambia] 2014). Data for this study were procured from the measure DHS project(The DHS Program - Available Datasets n.d.). Our analysis concentrates on women belonging to the 1965-1969 birth cohort aged 45-49 during data collection for the 2013-14 ZDHS round.

Eligibility was age-based thus neither marital status nor parity was a determinant for inclusion in the study. A total of 1020 women aged 45-49 in 2013 were enumerated. We conducted a retrospective analysis of how age at first marriage and age at first birth affect the CFS of women during their childbearing period.

\subsection{Measures}

\subsubsection{Outcome}

The number of children born alive to mothers of the 1965-1969 birth cohort provided an important entry point to understanding the reproductive behavior of this group of women. Thus, our outcome variable was CFS as measured by the number of live births to women age 45-49 in 2013-14. We categorized CFS to link childbirth to a specific age of the mother. We ended up with four categories for CFS; 0, 1-3, 4-5 and 6+ to cater for variations in women's reproductive behavior.

\subsubsection{Predictors}

The study utilized two main predictors; 1 ) age at first birth to investigate the extent to which age of the mother at birth of first child impacts on CFS and, 2) age at first marriage, to assess the influence marriage exerts on completed fertility. Due to concerns of legal marriage age, we considered segmenting the age of mother at first marriage predictor variable in two parts, i.e. those marrying before 18 and those marrying after age 18. Two other categories were constructed for those who marry before and after age 18; ages $<15$ and $15-18$ as well as ages $19-21$ and 22 and above. Similarly, in terms of age at first birth, we considered those having their first child before 18 and those after 18. 
This we, thought, should provide us with some understanding of differences in completed family size for women marrying early (before age 18) and those marrying at and after the legal age.

\subsubsection{Covariates}

Fertility among women varies greatly by socioeconomic characteristics. Traditionally, women with more education are more likely to have fewer children than those with no education. This proposition holds true for household wealth holding other factors constant. We included a list of covariates to control for the influence of socioeconomic factor in measuring this relationship. The variables identified as having an effect on CFS and thus considered for modeling were contraception use, education, place of residence and household wealth.

\subsubsection{Statistical analysis}

During data exploration, we noticed that the relationship between our outcome variable (CFS) and our predictor variables (age at first marriage and age at first birth) was nonlinear. Because of the non-linearity of CFS and the polytomous nature of its categories, we fitted a multinomial logistic regression (MLR) to measure the level and amount of association between our outcome and predictor variables. The MLR is similar to the binary logistic regression except that it is more versatile as it can handle an outcome variable with more than two categories. Added to this, MLR enables the building of a complex statistical model handling complex interrelated relationships of the response variable with more than two levels. To determine associations of the outcome variable with the predictor variables, descriptive analyses were performed mainly as proportions utilizing chi-square tests of proportions and results have been presented in terms of percentages with confidence intervals. We calculated the mean CFS for women in this study, their mean ages at birth and marriage as well as their confidence intervals. We also graphed our data using a fractional polynomial to illustrated predictor-outcome relationship. In building our MLR model, we first examined the relationship between each predictor variable (one at a time) and CFS through bivariate analysis (model 1). In model 2, we fitted a multivariate MLR model that included all predictor variables in model 1 i.e. mother's age at first marriage and mother's age at first birth and additionally controlled for potential confounders: education, place of residence, household wealth and contraceptive use. In model 3, we included all the variables that showed the strongest associations with the outcome but deliberately dropped mother's age at first marriage to check for the effect of correlation between the two predictor variables. In model 4, we brought back mother's age at first marriage and this time removed mother's age at first birth from analysis for the same reason as in model 3. We reported relative risk ratios (RRR) for all our models with their corresponding confident intervals at $95 \%$. All analyses were performed in Stata 14 (StataCorp LLC 2016).

\section{Results}

\subsection{Descriptive findings}

The 2014 ZDHS identified 1,020 women belonging to the 1965-1969 cohort aged between 45-49 during the survey. Our findings indicate that the average CFS was 6.7 (95\% CI: 6.5 - 6.9). The average age at sex debut for this cohort of women was 17 years (CI: $16.7-17.2$ ) while the mean age at first marriage and first birth were 18.3 and 18.9 respectively. Table 1, presents descriptive findings based of the characteristics of the respondents.

Table 1. Background characteristics of respondents.

\begin{tabular}{|c|c|c|c|c|}
\hline Variable & $n$ & Mean & $\begin{array}{l}\text { Standard } \\
\text { Error }\end{array}$ & $\begin{array}{c}\text { 95\% Confidence } \\
\text { Intervals }\end{array}$ \\
\hline Completed Family Size (CFS) & 1,020 & 6.7 & 0.093 & $6.5,6.9$ \\
\hline Age of respondent at first birth & 995 & 18.9 & 0.120 & $18.7,19.1$ \\
\hline Age at first Marriage & 1012 & 18.3 & 0.142 & $18.0,18.5$ \\
\hline
\end{tabular}




\begin{tabular}{|c|c|c|c|c|}
\hline Age at first sex (Sexual debut) & 543 & 17.0 & 0.127 & $16.7,17.2$ \\
\hline $\begin{array}{c}\text { Age of women aged } 45-49 \text { in single } \\
\text { years }\end{array}$ & 1,020 & 47.0 & 0.047 & $46.9,47.1$ \\
\hline
\end{tabular}

In terms of contraceptive use, over half $(53.2 \%$; CI: $50.5-56.8)$ reported ever using a method of contraception to prevent pregnancy. Almost two-thirds (58.7\%; CI: $55.6-61.8$ ) of respondents were rural dwellers. Fifty-three percent (CI: 49.5 - 55.7) had no education followed by $39.7 \%$ (CI: $36.7-$ 42.8) with primary education. The remaining 3.0\% (CI: $2.0-4.2)$ and $4.7 \%$ (CI: $3.5-6.2)$ had secondary and tertiary education respectively as presented in table 2 .

Table 2. Chi-square test of difference in proportions of completed family size.

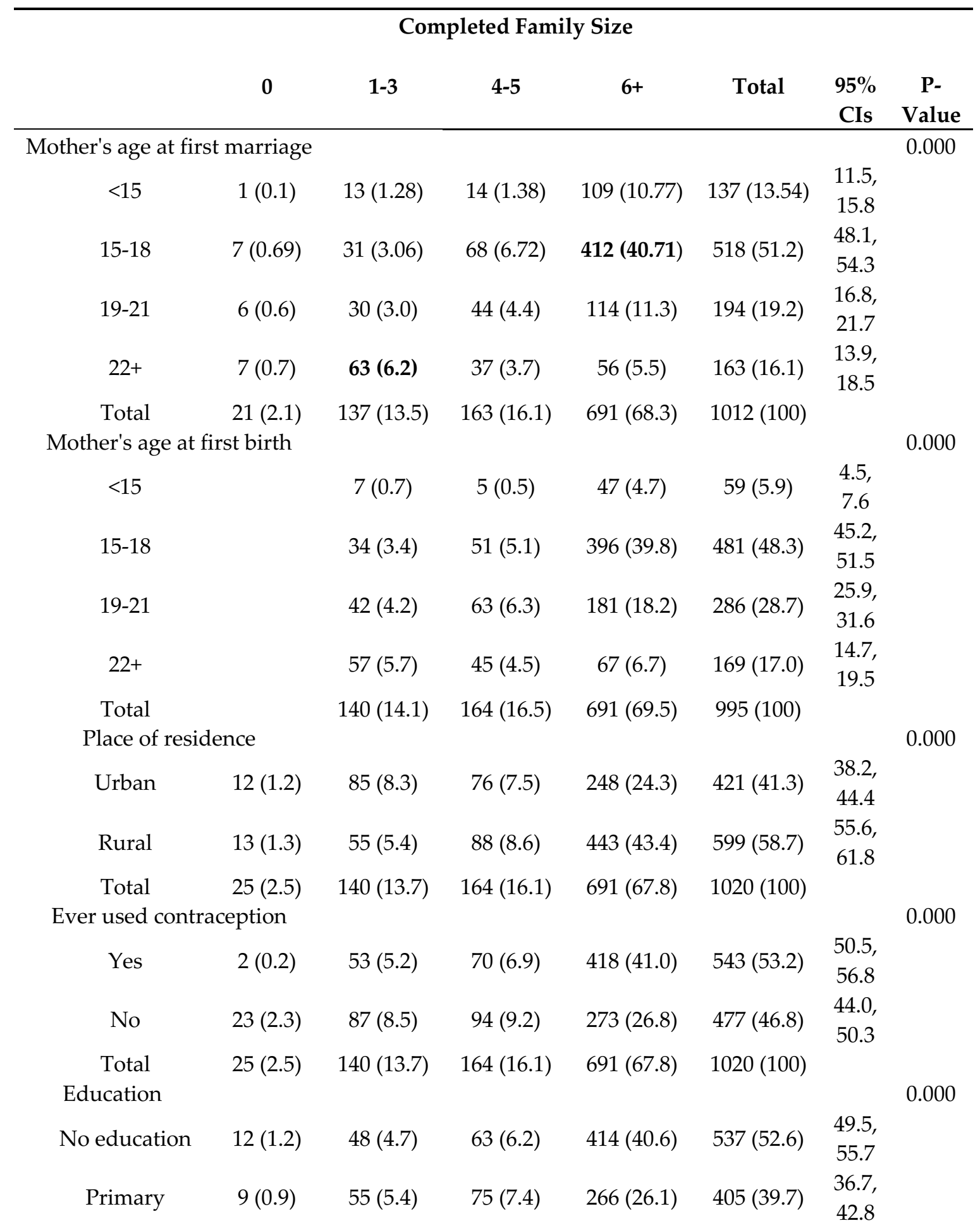




$\begin{array}{ccccccc}\text { Secondary } & 1(0.1) & 13(1.3) & 11(1.1) & 5(0.5) & 30(3.0) & 2.0, \\ & & & & & & 4.2 \\ \text { Tertiary } & 3(0.3) & 24(2.4) & 15(1.5) & 6(0.6) & 48(4.7) & 3.5, \\ \text { Total } & 25(2.5) & 140(13.7) & 16416.1) & 691(67.8) & 1020(100) & \end{array}$

Household wealth

0.000

\begin{tabular}{lcccccc} 
Lowest & $4(0.39)$ & $16(1.57)$ & $31(3.04)$ & $135(13.24)$ & $186(18.24)$ & 15.9, \\
& & & & & & 20.7 \\
Second & $1(0.1)$ & $19(1.86)$ & $28(2.75)$ & $158(15.49)$ & $206(20.2)$ & 17.8, \\
& & & & & & 22.8 \\
Middle & $6(0.59)$ & $19(1.86)$ & $31(3.04)$ & $173(16.96)$ & $229(22.45)$ & 19.9, \\
& & & & & & 25.1 \\
Fourth & $5(0.49)$ & $25(2.45)$ & $34(3.33)$ & $138(13.53)$ & $202(19.8)$ & 17.4, \\
& & & & & & 22.4 \\
Highest & $9(0.88)$ & $61(5.98)$ & $40(3.92)$ & $87(8.53)$ & $197(19.31)$ & 16.9, \\
Total & $25(2.45)$ & $140(13.73$ & $164(16.08)$ & $691(67.75)$ & $1020(100)$ & \\
\hline
\end{tabular}

A chi-square test of differences in proportions in table 2 above shows association of mother's characteristics and CFS. All the Pearson's chi-square tests resulted in statistically significant associations between each characteristic of the mother and CFS.

Figure 1. Completed Family Size by Age at First Marriage and Residence.

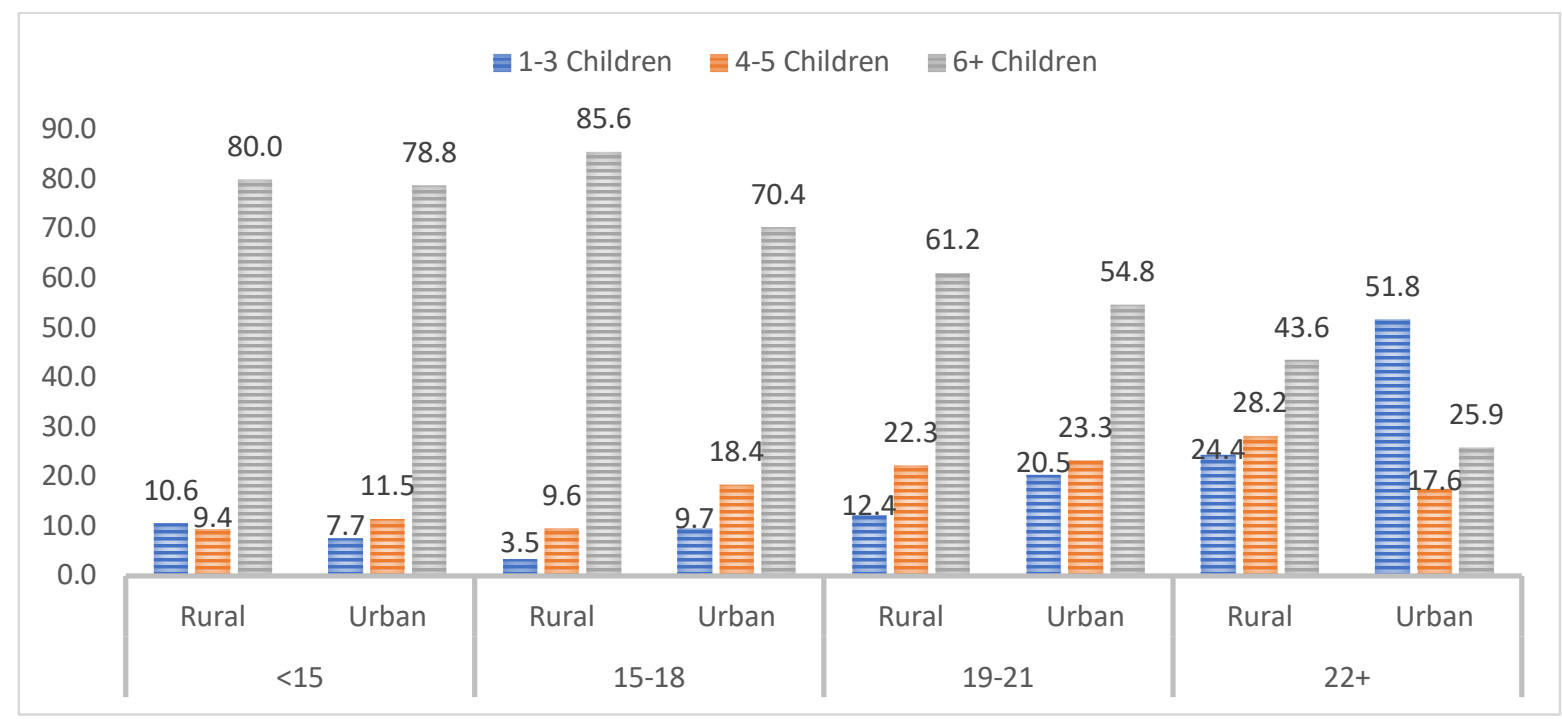

A comparison of the effect age at first marriage and place of residence revealed that regardless of dwelling place, more women that got married before age 15 and those that married between ages 15 and 18 ended up with 6 and more children than those marrying after age 18. A small proportion $(25.9 \%)$ of women who bore 6 or more children were those from urban areas that got married after age 21. Figure 1 further demonstrates that more than half $(51.8 \%)$ of urban women marring at ages above 21 had 1-3 children compared to their rural compatriots at only $24.4 \%$. For all ages at marriage except before age 15, the proportion of women who had 1-3 children is lower for rural compared to urban areas. Figure 1 provides details of the relationship between age at first marriage and CFS for urban and rural women aged 45-49.

Figure 2. Completed Family Size by Mother's Age at First Birth and Residence. 


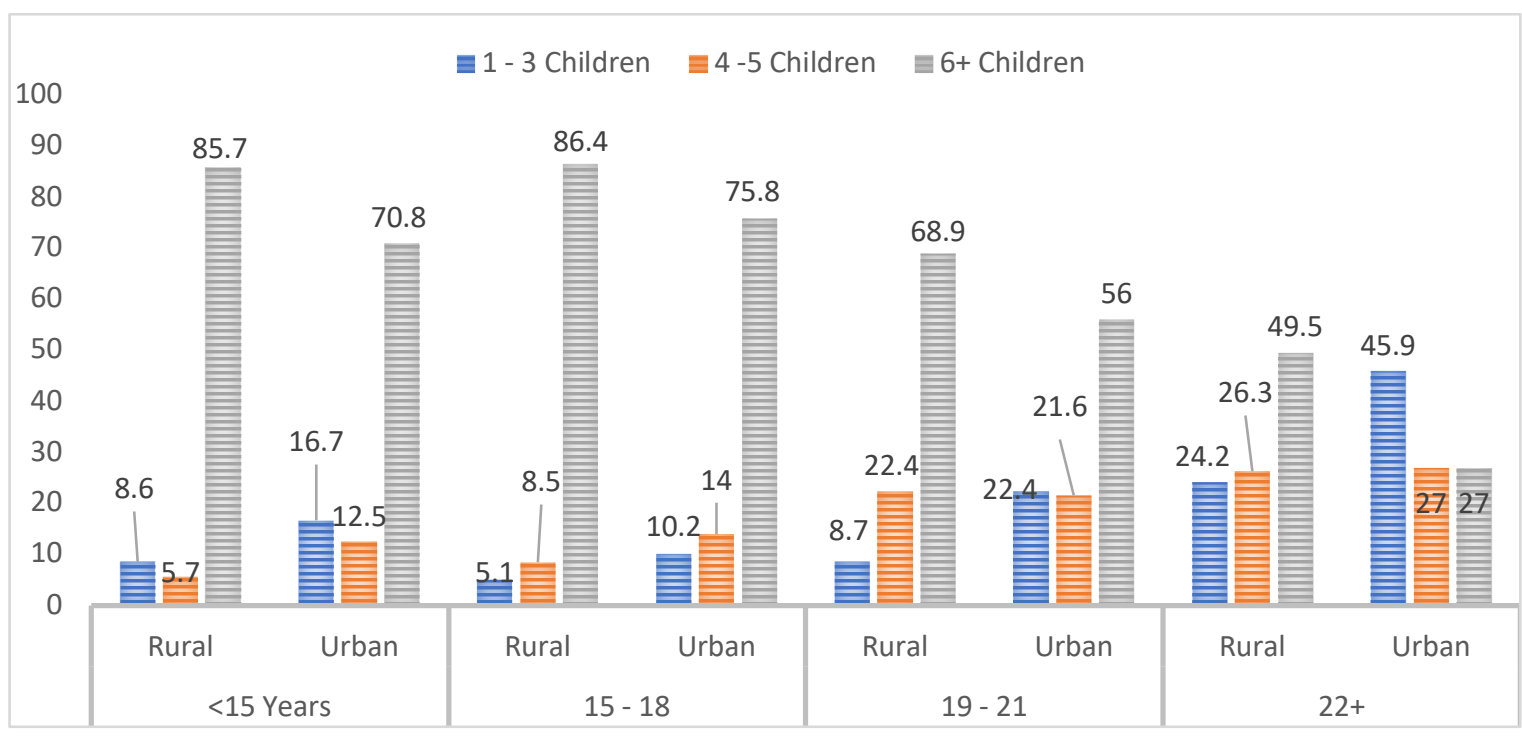

Analysis by place of residence illustrates that, both urban and rural women exhibit a distinct pattern of CFS. The proportions of rural women with 6 or more children were relatively higher for all ages at first birth when compared with their urban counterparts. For instance, the proportions of women having 6 or more children increased with age at first birth from $85.7 \%$ for those who had their first birth before age 15 to $86.4 \%$ for those who had their first birth at ages between 15 and 18 inclusive. As age at first birth increases, higher order births gradually diminish while proportions rise for lower order births. Figure 2, depicts this scenario.

The association between age at first marriage and age at first birth on the hand with CFS on the other was graphically modeled in a fractional polynomial to show the predicted curve of the relationship. Figure 3 shows that for both age at first marriage and age at first birth, CFS declined age at first occurrence of the event increased. Both ages at first marriage as well as first birth were relatively low at around ages 10-12 with about 6-7 children then increased to a peak at around 15-18 with about 8 children. As age rose to above 19, CFS exhibited a corresponding declining effect from around 7 down to 2 children. See figure 3 (A and B).

Figure 3. Relationship between age at first birth as well as age at first marriage with children ever born.

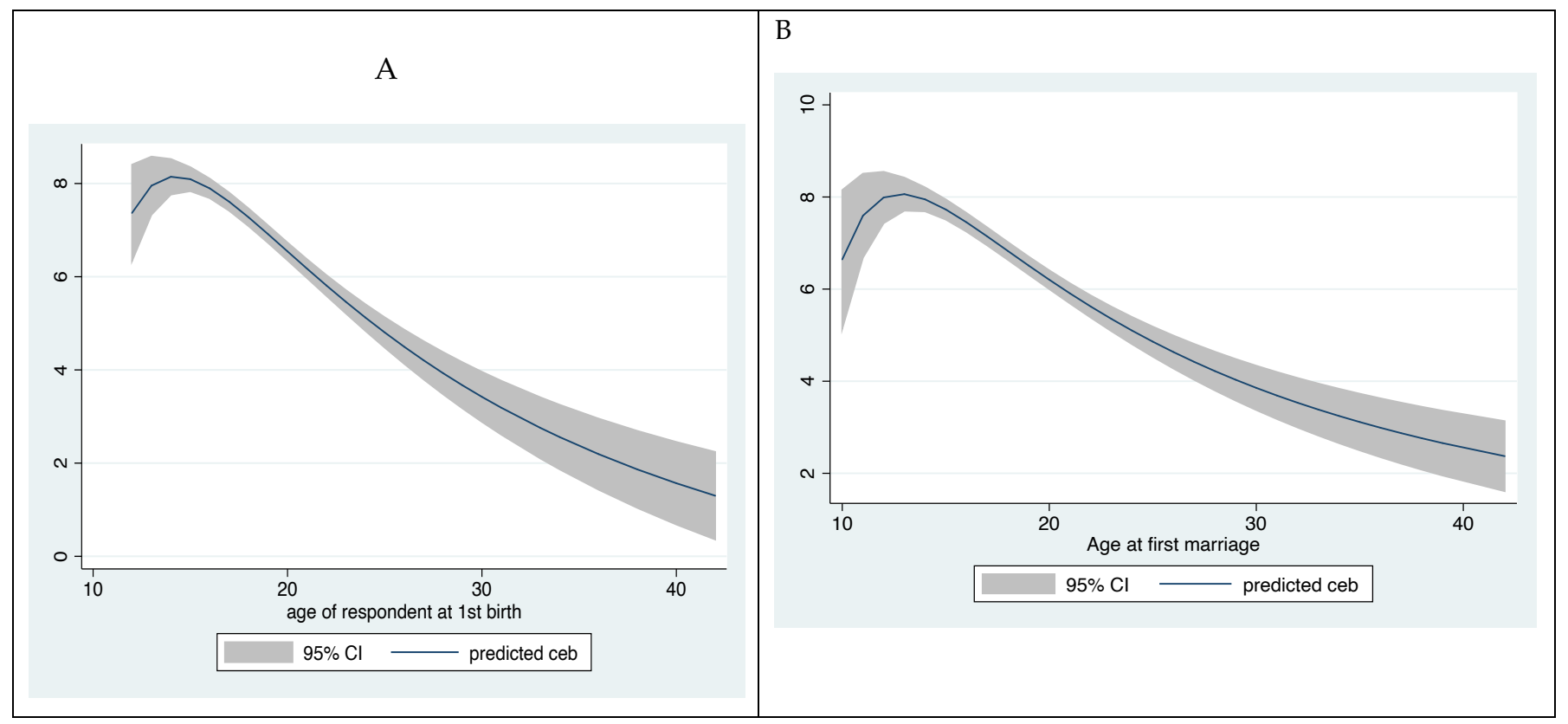

4.2. Bivariate analysis 
We can infer from model 1 that women who married before age 15 and 15-18 were less likely to have no children by the end of their reproductive cycle. However, the risk of having no children than 6 or more children was 17.6 times greater for women that had never used contraceptive relative to those that had ever used contraceptives holding all other factors constant. Education (no education [RRR: 0.073; 95\% CI: 0.009-0.611] and primary [RRR: 0.136; 95\% CI: 0.064-0.402]) and household wealth (lowest, second, and middle) were all statistically significant signifying a relationship when CFS was 0 . The risk of having 1-3 children compared to 6 or more children was $89.4 \%, 93.3 \%$ and $76.6 \%$ lower for women whose ages at first marriage were $<15,15-18$ and 19-21 respectively relative to $22+$.

The other characteristics that had statistically significant associations were ever used contraceptives, education (no education and primary), place of residence and household wealth. See table 1 for details.

Table 2. Model 1: Bivariate multinomial regression of children ever born by characteristics of mother.

\begin{tabular}{|c|c|c|c|}
\hline \multirow{2}{*}{$\begin{array}{c}\text { Children ever born } \\
0 \text { Children }\end{array}$} & \multirow[t]{2}{*}{ RRR } & \multicolumn{2}{|c|}{ 95\% Confidence Intervals } \\
\hline \multirow{2}{*}{\multicolumn{4}{|c|}{ Age at first marriage }} \\
\hline & & & \\
\hline$<15$ & $0.073^{*}$ & 0.009 & 0.611 \\
\hline $15-18$ & $0.136^{* * *}$ & 0.046 & 0.402 \\
\hline $19-21$ & 0.421 & 0.135 & 1.312 \\
\hline \multicolumn{4}{|l|}{$22+$ (Reference) } \\
\hline \multicolumn{4}{|l|}{ Ever used Contraception } \\
\hline No & $17.608^{* * *}$ & 4.118 & 75.286 \\
\hline \multicolumn{4}{|l|}{ Yes (Reference) } \\
\hline \multicolumn{4}{|l|}{ Education attainment } \\
\hline No education & $0.058^{* * *}$ & 0.013 & 0.260 \\
\hline Primary & $0.068^{* *}$ & 0.015 & 0.315 \\
\hline Secondary & 0.400 & 0.031 & 5.151 \\
\hline \multicolumn{4}{|l|}{ Tertiary (Reference) } \\
\hline \multicolumn{4}{|l|}{ Place of residence } \\
\hline Rural & 0.606 & 0.273 & 1.350 \\
\hline \multicolumn{4}{|l|}{ Urban (Reference) } \\
\hline \multicolumn{4}{|l|}{ Household Wealth } \\
\hline Lowest & $0.286^{*}$ & 0.086 & 0.959 \\
\hline Second & $0.061^{* *}$ & 0.008 & 0.491 \\
\hline Middle & $0.335^{*}$ & 0.116 & 0.972 \\
\hline Fourth & 0.350 & 0.114 & 1.080 \\
\hline \multicolumn{4}{|l|}{ Highest (Reference) } \\
\hline \multicolumn{4}{|l|}{ 1-3 Children } \\
\hline \multicolumn{4}{|l|}{ Age at first birth } \\
\hline$<15$ & $0.175^{* * *}$ & 0.073 & 0.417 \\
\hline $15-18$ & $0.101^{* * *}$ & 0.061 & 0.166 \\
\hline $19-21$ & $0.273^{* * *}$ & 0.168 & 0.444 \\
\hline \multicolumn{4}{|l|}{$22+$ (Reference) } \\
\hline \multicolumn{4}{|l|}{ Age at first marriage } \\
\hline$<15$ & $0.106^{* * *}$ & 0.054 & 0.209 \\
\hline $15-18$ & $0.067^{* * *}$ & 0.040 & 0.112 \\
\hline $19-21$ & $0.234^{* * *}$ & 0.136 & 0.401 \\
\hline $22+$ (Reference) & & & \\
\hline
\end{tabular}

Ever used Contraception

No 
Yes (Reference)

\begin{tabular}{|c|c|c|c|}
\hline Education attainme & & & \\
\hline No education & $0.029^{* * *}$ & 0.011 & 0.074 \\
\hline Primary & $0.052^{* * *}$ & 0.020 & 0.132 \\
\hline Secondary & 0.650 & 0.166 & 2.546 \\
\hline \multicolumn{4}{|l|}{ Tertiary (Reference) } \\
\hline \multicolumn{4}{|l|}{ Place of residence } \\
\hline Rural & $0.362^{* * *}$ & 0.249 & 0.526 \\
\hline \multicolumn{4}{|l|}{ Urban (Reference) } \\
\hline \multicolumn{4}{|l|}{ Household Wealth } \\
\hline Lowest & $0.169^{* * *}$ & 0.092 & 0.312 \\
\hline Second & $0.172^{* * *}$ & 0.096 & 0.306 \\
\hline Middle & $0.157^{* * *}$ & 0.088 & 0.279 \\
\hline Fourth & $0.258^{* * *}$ & 0.151 & 0.442 \\
\hline \multicolumn{4}{|l|}{ Highest (Reference) } \\
\hline \multicolumn{4}{|l|}{ 4-5 Children } \\
\hline \multicolumn{4}{|l|}{ Age at first birth } \\
\hline$<15$ & $0.158^{* * *}$ & 0.058 & 0.429 \\
\hline $15-18$ & $0.192^{* * *}$ & 0.119 & 0.309 \\
\hline $19-21$ & $0.518^{* *}$ & 0.323 & 0.833 \\
\hline \multicolumn{4}{|l|}{$22+$ (Reference) } \\
\hline \multicolumn{4}{|l|}{ Age at first marriage } \\
\hline$<15$ & $0.194^{* * *}$ & 0.097 & 0.389 \\
\hline $15-18$ & $0.250^{* * *}$ & 0.153 & 0.407 \\
\hline $19-21$ & 0.584 & 0.340 & 1.004 \\
\hline \multicolumn{4}{|l|}{$22+$ (Reference) } \\
\hline \multicolumn{4}{|c|}{ Ever used Contraception } \\
\hline No & $2.056^{* * *}$ & 1.456 & 2.903 \\
\hline \multicolumn{4}{|l|}{ Yes (Reference) } \\
\hline \multicolumn{4}{|c|}{ Education attainment } \\
\hline No education & $0.061^{* * *}$ & 0.023 & 0.163 \\
\hline Primary & $0.113^{* * *}$ & 0.042 & 0.301 \\
\hline Secondary & 0.880 & 0.213 & 3.637 \\
\hline \multicolumn{4}{|l|}{ Tertiary (Reference) } \\
\hline \multicolumn{4}{|l|}{ Place of residence } \\
\hline Rural & $0.648^{*}$ & 0.460 & 0.914 \\
\hline \multicolumn{4}{|l|}{ Urban (Reference) } \\
\hline \multicolumn{4}{|l|}{ Household Wealth } \\
\hline Lowest & $0.499^{*}$ & 0.291 & 0.858 \\
\hline Second & $0.385^{* *}$ & 0.223 & 0.668 \\
\hline Middle & $0.390^{* *}$ & 0.228 & 0.666 \\
\hline Fourth & $0.536^{*}$ & 0.315 & 0.911 \\
\hline \multicolumn{4}{|l|}{ Highest (Reference) } \\
\hline $6+$ & & Base ou & \\
\hline
\end{tabular}

\subsection{Multivariate analysis}

Table 4 presents multivariate MLR determining the relationship between CFS and the characteristics of the mother. When both the mother's age at first marriage and at first birth were simultaneously included in the regression model (Model 2), the results related to 0 births were redundant because first birth is normally preceded by marriage. While in Model 3 mother's age at first marriage is omitted from the model hence the missing coefficients, model 2 included all the 
predictor variables and covariates. Statistical significance was established for mother's age at first birth (15-18), mother's age at first marriage, ever used contraception, education (no education and primary, and household wealth when CFS was 1-3 children. The risk of having 1-3 children compared to 6 or more children was lower for all ages at first marriage relative to women aged above 22 years at first marriage. For mother's age at first birth, the risk of 1-3 children was only statistically significant for women aged 15-18 (RRR: 0.382; 95\% CI: 0.194-1.254). For 4-5 children, mother's age at marriage, place of residence and household wealth were statistically non-significant. Model 3 omitted mother's age at first marriage and household wealth from the model which strengthened the model as all coefficients were statistically significant for almost all categories. Model 4 includes the mother's age at first marriage and omitted household wealth and residence. The estimates were all statistically significant except for education when CFS is 0 . Table 4 details the results of the models.

Table 4. Multivariate multinomial regression of children ever born by characteristics of the mother.

\begin{tabular}{|c|c|c|c|c|c|c|c|c|c|}
\hline \multirow[b]{2}{*}{ Completed family size } & \multicolumn{3}{|c|}{ Model 2} & \multicolumn{3}{|c|}{ Model 3} & \multicolumn{3}{|c|}{ Model 4} \\
\hline & \multirow[t]{2}{*}{ RRR } & \multicolumn{2}{|c|}{ 95\% Confidence Intervals } & \multirow[t]{2}{*}{ RRR } & \multicolumn{2}{|c|}{ 95\% Confidence Intervals } & \multirow[t]{2}{*}{ RRR } & \multicolumn{2}{|c|}{ 95\% Confidence Intervals } \\
\hline \multirow{2}{*}{\multicolumn{10}{|c|}{ Age at first marriage }} \\
\hline & & & & & & & & & \\
\hline$<15$ & & & & & & & $0.058^{* *}$ & 0.007 & 0.498 \\
\hline $15-18$ & & & & & & & $0.131^{* * *}$ & 0.043 & 0.400 \\
\hline $19-21$ & & & & & & & 0.394 & 0.122 & 1.272 \\
\hline \multicolumn{10}{|l|}{ Ever used Contraception } \\
\hline No & & & & & & & $36.107^{* *}$ & 4.729 & 275.666 \\
\hline \multicolumn{10}{|l|}{ Education attainment } \\
\hline No education & & & & & & & 32424.530 & 0.000 & . \\
\hline Primary & & & & & & & 57098.630 & 0.000 & . \\
\hline Secondary & & & & & & & 1.239 & 0.000 & . \\
\hline \multicolumn{10}{|l|}{ 1-3 Children } \\
\hline \multicolumn{10}{|l|}{ Age at first birth } \\
\hline$<15$ & 0.387 & 0.119 & 1.254 & $0.224^{* *}$ & 0.088 & 0.570 & & & \\
\hline $15-18$ & $0.382^{* *}$ & 0.194 & 0.752 & $0.152^{* * *}$ & 0.088 & 0.263 & & & \\
\hline $19-21$ & 0.682 & 0.364 & 1.278 & $0.359^{* * *}$ & 0.208 & 0.619 & & & \\
\hline \multicolumn{10}{|l|}{$22+$ (Reference) } \\
\hline \multicolumn{10}{|l|}{ Age at first marriage } \\
\hline$<15$ & $0.254^{* *}$ & 0.102 & 0.633 & & & & $0.153^{* * *}$ & 0.074 & 0.319 \\
\hline $15-18$ & $0.143^{* * *}$ & 0.074 & 0.277 & & & & $0.102^{* * *}$ & 0.058 & 0.179 \\
\hline $19-21$ & $0.305^{* * *}$ & 0.160 & 0.582 & & & & $0.268^{* * *}$ & 0.148 & 0.484 \\
\hline \multicolumn{10}{|l|}{$22+$ (Reference) } \\
\hline \multicolumn{10}{|l|}{ Ever used Contraception } \\
\hline $\begin{array}{c}\text { No } \\
\text { Yes (Reference) }\end{array}$ & $6.975^{* * *}$ & 4.141 & 11.749 & $5.137^{* * *}$ & 3.222 & 8.191 & $5.253^{* * *}$ & 3.250 & 8.492 \\
\hline Education attainment & & & & & & & & & \\
\hline No education & $0.120^{* * *}$ & 0.037 & 0.392 & $0.024^{* * *}$ & 0.009 & 0.069 & $0.031^{* * *}$ & 0.011 & 0.089 \\
\hline Primary & $0.168^{* *}$ & 0.057 & 0.493 & $0.064^{* * *}$ & 0.023 & 0.177 & $0.067^{* * *}$ & 0.024 & 0.186 \\
\hline Secondary & 1.088 & 0.247 & 4.793 & 0.880 & 0.208 & 3.727 & 0.756 & 0.177 & 3.229 \\
\hline Tertiary (Reference) & & & & & & & & & \\
\hline Place of residence & & & & & & & & & \\
\hline Rural & 0.764 & 0.410 & 1.425 & & & & & & \\
\hline Urban (Reference) & & & & & & & & & \\
\hline Household Wealth & & & & & & & & & \\
\hline Lowest & $0.211^{* *}$ & 0.074 & 0.600 & & & & & & \\
\hline Second & $0.241^{* *}$ & 0.094 & 0.623 & & & & & & \\
\hline Middle & $0.276^{* *}$ & 0.120 & 0.637 & & & & & & \\
\hline Fourth & $0.326^{* *}$ & 0.159 & 0.669 & & & & & & \\
\hline Highest (Reference) & & & & & & & & & \\
\hline 4-5 Children & & & & & & & & & \\
\hline Age at first birth & & & & & & & & & \\
\hline$<15$ & $0.219^{*}$ & 0.068 & 0.711 & $0.176^{* *}$ & 0.063 & 0.497 & & & \\
\hline $15-18$ & $0.320^{* * *}$ & 0.176 & 0.581 & $0.247^{* * *}$ & 0.148 & 0.412 & & & \\
\hline $19-21$ & 0.731 & 0.419 & 1.274 & 0.619 & 0.372 & 1.030 & & & \\
\hline Age at first marriage & & & & & & & & & \\
\hline$<15$ & 0.620 & 0.261 & 1.471 & & & & $0.262^{* * *}$ & 0.126 & 0.547 \\
\hline $15-18$ & 0.566 & 0.308 & 1.038 & & & & $0.349^{* * *}$ & 0.205 & 0.592 \\
\hline
\end{tabular}




\begin{tabular}{|c|c|c|c|c|c|c|c|c|c|}
\hline $19-21$ & 0.695 & 0.376 & 1.283 & & & & 0.643 & 0.361 & 1.145 \\
\hline \multicolumn{10}{|c|}{ Ever used Contraception } \\
\hline No & $3.295^{* * *}$ & 2.197 & 4.943 & $3.277^{* * *}$ & 2.211 & 4.856 & $3.227^{* * *}$ & 2.186 & 4.765 \\
\hline \multicolumn{10}{|c|}{ Education attainment } \\
\hline No education & $0.082^{* * *}$ & 0.026 & 0.261 & $0.059^{* * *}$ & 0.021 & 0.167 & $0.058^{* * *}$ & 0.021 & 0.165 \\
\hline Primary & $0.182^{* *}$ & 0.062 & 0.536 & $0.142^{* * *}$ & 0.051 & 0.393 & $0.131^{* * *}$ & 0.048 & 0.363 \\
\hline Secondary & 1.200 & 0.275 & 5.232 & 1.173 & 0.269 & 5.107 & 0.998 & 0.233 & 4.267 \\
\hline \multicolumn{10}{|l|}{ Place of residence } \\
\hline Rural & 0.824 & 0.489 & 1.388 & & & & & & \\
\hline \multicolumn{10}{|l|}{ Household Wealth } \\
\hline Lowest & 1.031 & 0.432 & 2.463 & & & & & & \\
\hline Second & 0.829 & 0.368 & 1.871 & & & & & & \\
\hline Middle & 0.805 & 0.388 & 1.671 & & & & & & \\
\hline Fourth & 0.913 & 0.481 & 1.734 & & & & & & \\
\hline $6+$ & & & & & Base ou & & & & \\
\hline
\end{tabular}

${ }^{* * *} \mathrm{P}<0 \cdot 001 ;{ }^{* *} \mathrm{P}$ is $<0 \cdot 01$ and $\geq 0 \cdot 001 ;{ }^{*} \mathrm{P} \leq 0 \cdot 05$ and $\geq 0 \cdot 01$.

Of particular interest in Model 4 was that women who got married before age 15 and between 15 and 18 years were less likely $(94.2 \%$ and $86.9 \%)$ to have no children than 6 children compared to women that married after age 22. RRRs for model 2 and 3 for the respective variables were similar.

\section{Discussion}

This study followed the birth history of 1020 women born during the 1965-1969 cohort based on retrospective data. Our results show that the average CFS was 6.7 (95\% CI: $6.5-6.9)$ and that mean age at first marriage and first birth were 18.3 (95\% CI: 18.0 - 18.5) and 18.9 (95\% CI: 18.7 - 19.1) respectively. The average age at sexual debut for this cohort was 17 years (95\% CI: 16.7 - 17.2). About $11 \%$ of women with CFS above 6 children married before age 15 and $5 \%$ had their first birth within the same age range. Higher CFS of 6 or more children were concentrated among women whose age at first marriage and birth was between 15 and 18 years old (40.7 and 39.8\% respectively. Women marrying at younger ages and having their first birth at younger ages were more likely to have higher CFS than compatriots that initiated both marriage and childbearing at or after age 22. Having no education, being a rural dweller and having medium household wealth all reduced the risk of having lower CFS relative to 6 or more children.

The main strength of this study is it followed a cohort of women who had or were about to complete their reproductive cycle and collected fertility information about this group in a manner that provided grounds for exploring determinants. It also controlled for socioeconomic factors to effectively discern associations. Furthermore, the use of probability sampling in the collection of this data gives this study sufficient leverage to generalize findings to the entire 1965-1969 cohort. However, our study also presents some limitations. As are all surveys that depend on retrospective responses, self-reported data may introduce biases such as social desirability bias, non-response bias, recall bias, interviewer bias etc., even in the presence of exceptionally trained enumerators and rigorous probing to encourage accuracy of reporting (Erens et al. 2014; Sedgwick 2014; Setia 2016). The primary limitation of the cross-sectional study design is that because the exposure and outcome are simultaneously assessed, there is generally no evidence of a temporal relationship between exposure and outcome (Carlson and Morrison 2009; Setia 2016). Being a cross sectional survey, ZDHS's ability to measure relationships of causality in nature is limited. For example, the relationship between education attainment and CFS in the survey is masked by heterogeneous factors, including reverse causality (C.J.Mann 2003; Setia 2016).

Understanding changes in CFS is an important indicator of the anticipated future in lifetime fertility behavior of women. Factors that influence these changes become cornerstones for predicting fertility behavior and determining population growth. This study found a CFS of 6.7 children for the 1965-1969 birth cohort based on retrospective data analysis. This finding is consistent with results from the 2013-14 ZDHS that also found the average number of children ever born was 6.7 for women nearing the end of their childbearing cycle and 7.3 for those currently married, alluding the difference in the two measures to lower fertility among the young unmarried women (Central Statistical Office 
et al. 2015) in the former index. This CFS is higher than the current TFR for most African countries including Zambia itself (Bongaarts, Mensch, and Blanc 2017; Gilles Pison 2017). TFR in Zambia reduced from 6.1 in 1992, 5.9 in 2010, 5.3 in 2014 to 4.7 in 2018 (Central Statistical Office (CSO) [Zambia], Ministry of Health (MOH) [Zambia] 2014; Central Statistical Office Zambia (CSO) 2010; University of Zambia (UNZA), Central Statistical Office (CSO), and Macro International Inc. 1993; Zambia Statistical Agency (ZSA) et al. 2019). Though fertility has been declining in Africa, it remains high in comparison to other regions (Gilles Pison n.d.). The CFS is the major determinant of the average household size that remains high in most African countries (United Nation Department of Economic and Social Affairs 2017). The household size in Zambia is high at 5.1 persons (urban 4.8 and rural 5.4) (Central Statistical Office, Ministry of Health, University of Zambia Teaching Hospital, Tropical diseases Research Centre, University of Zambia 2015) relative to the TFR of 4.7 children. TFRs in the African region averaged 4.7 between 2010 and 2015 which is far above the global average of 2.5 though it is expected to drop by 2050, but will still be well above the rest of the world (United Nations Children's Fund (UNICEF) 2014). This high TFR fuels the next generation of mothers who will have fewer children than their preceding cohorts, but still more than the rest of the world. At this rate of fertility change, Africa will constitute $41 \%$ of the world's population and $40 \%$ of global under-five children by 2050 (Gilles Pison n.d.; United Nations Children's Fund (UNICEF) 2014, n.d.).

Our study further found that women from the 1965-1969 cohort married early (mean=18.3; CI: 18.0-18.5) and that by the end of their reproductive life, $68.3 \%$ of them had birthed 6 children or more. With changes in reproductive behaviors overtime, this rate is expected to be lower for future cohorts. In fact, a study conducted in Malawi found that older cohorts have higher fertility levels than younger ones (Manda and Meyer 2018). As expected, marriage plays a crucial role in shaping the course of fertility, especially in the developing world (Bongaarts, Mensch, and Blanc 2017). The timing of marriage predominantly regulates how many children will be born since marriage is the only institution that sanctions reproduction. Over half (51.2\%; CI: 48.1-54.3) of the women from our study cohort married between age 15 and 18 and a substantial number (13.5\% CI:11.5-15.8) married at ages below 15 years. Our calculations reveal that almost two-thirds (64.7\%) of women from this cohort were married off when they were still underage exposing them to a long period of risk of childbearing. Fifty-one percent of women with 6 or more children got married by age 18. Studies have shown that women that marry early (mostly victims of child marriages), start childbearing early, remain at risk of childbearing for longer periods of times and have poor health outcomes than their counterparts who marry later (Jayaraman, Gebreselassie, and Chandrasekhar 2009; Maswikwa et al. 2015). The timing of marriage in Zambia is affected by a myriad of socioeconomic factors, including education, wealth, social status and cultural responsibility that influence CFS. This study found that the cohort under investigation generally had more children, but the probability of having fewer children was higher for urban women than rural women. To put this into perspective, one study investigated how household economic hard times affect the time of marrying off their children especially in Africa where payment for marriage, whether in cash or kind, is widespread. They found that parents tactfully selected the time for their children's marriage depending on household economic instability thus affecting age at marriage as the payments for marriage constitute a vital source for "consumption smoothing" for the bride's family (Corno, Hildebrandt, and Voena 2017).

The time an individual starts parenthood is one of life's most challenging yet significant occurrences. It indicates the launch of responsibility for providing and maintaining wellbeing and success for the current and future generations (Bongaarts and Blanc 2015). A woman's age at first birth have grave implications for a roller coaster of life events such as education, work-life and completed family size. The results of this study found that the mean age at first birth for the cohort was 0.6 years higher than for marriage and 1.9 years higher than for sex debut. This finding suggests that the birth of the first child, in most instances, was preceded by sexual debut and then marriage. Similar analysis but for 43 countries found that the mean age at first birth was greater than the mean age at first marriage, which was also greater than the mean age at first sex for all regions (Bongaarts, Mensch, and Blanc 2017). A similar study conducted in Pakistan found that hazard of birth increased in the first two years following marriage and their after declined (Gangadharan and Maitra 2003). 
Several studies in the region posit that the mean age at first birth in sub Saharan Africa is about 21 with most West and Middle African countries having age at first birth at or below 18 years while East and Southern African countries above 22 years (Bongaarts, Mensch, and Blanc 2017; Mensch, Grant, and Blanc 2006). The increasingly rising age at first birth in most African countries could be as a result of improved education outcomes for women which would translate in better health and reduced risks of maternal related morbidity and mortality and manageable fertility.

Another significant aspect that affects CFS is education of women. We found that women with no education and primary education ( $52 \%$ and $39.7 \%$ respectively) tended to have more children than those with secondary (3\%) and tertiary education (4.7\%). Even though noticeable progress has been attained, rural areas of sub-Saharan Africa still display low education levels for women (Bongaarts, Mensch, and Blanc 2017; Channon and Harper 2019). Thus, the education atmosphere is not favorable to any meaningful change in CFS for rural women in the region (Jayaraman, Gebreselassie, and Chandrasekhar 2009; Manda and Meyer 2018). Not only does education delay age at first birth, it also enhances the power of choice among women such that their consumption patterns enable them to live healthy and pursue healthy choices in child rearing (Bongaarts, Mensch, and Blanc 2017). Our findings show that in all the models, education attainment was inversely related to CFS. The lower the education level attained, the higher the CFS; but age at first marriage and first birth are positively related to education level attained. This, however, is expected as women who attend secondary and tertiary education are selective, such that the timing at which events occur intersect and compete with schooling age; much more in post primary than primary ${ }^{49,50}$. Numerous reasons have been advanced that cause the inverse relationship between a woman's education and fertility that include but not limited to superior autonomy among women, exposure to new gender norms and childbearing practices, improvement in information acquiring useful in women's health and their offspring. Women with more education are also elective in partner choice, have higher need for wealth and understand the costs that accrue or are forgone in timing of reproductive events.

Relatedly, women that reported having never used contraception were 5.3 (95\% CI:3.3 - 8.5) more likely to have 1-3 children than 6 or more children compared to participants that have ever used contraceptive. This is an expected result because the variable "Ever used contraception" does not measure frequency of contraceptive use during the active childbearing years nor does it measure current use for those still bearing children. Added, $64.7 \%$ of the women started childbearing at or before age 18 implying they did not complete sufficient education to appreciate the effectiveness and benefits of using contraceptives. The best way of understanding the effect of contraceptive use on CFS is to retrospectively investigate the frequency and reasons for contraceptive use for women at the height of their childbearing career. Education has also been cited as a source of instruments necessary for obtaining information that enhances women and girls' ability of comprehending and learning information regarding contraceptive use and the benefits of smaller families. It could be because education is not as widespread in rural areas that women there exhibited higher fertility behaviors than their urban counterparts. In terms of household wealth, our results indicate that the distribution of women by household wealth did not vary much. The range was $18.2 \%$ (95\%CI: $159-$ 20-7) for lowest to $22.5 \%$ (95\% CI: 19.9-25.1). Within household wealth classes, the highest proportions were recorded among women with 6 or more children. Table 4 model 2 shows that the higher the household wealth the less the risk of having 1-3 children relative to 6 or more children. The relationship between household wealth and CFS when CFS is 4-5 children was statistically not significant. This outcome could be as a result of measuring household wealth as current and not at during their childbearing years or at the beginning of the childbearing period. Retrospective studies have this limitation in linking duration measures to point estimates.

\section{Conclusion}

Our findings align with several previous studies accentuating an inverse association between mother's age at marriage and first birth to CFS. Women that marry before age 18 have a higher likelihood of having 6 or more children by the end of the reproductive period than their peers who marry later. Marriage, by and large, is a single most significant predictor of CFS. Holding other factors 
constant, women who initiate child birth early have higher CFS related to those that start late. Several determinants are at play here including the fertility inhibiting nature of education, consistence contraception use, rural-urban residence and household wealth, especially at the time of child bearing initiation. It is expected that the timing of events will keep rising as improvements in education, contraception use and wealth are sustained among the women folk. Education is seen as the most important covariate as the changes in other variables are strongly affected by education attainment. Thus, improvements in general education, especially one that promotes post primary education among women will contribute significantly to a rise in timing of reproductive events. Studies have shown that girls that marry early are not only at risk of rapidly repeated births but also of diseases and poor health. Generally, girls who marry young have lower levels of education attainment, lower labor force participation and inferior economic ventures (Behrman and Jejeebhoy 1996; Field and Ambrus 2008; Wang et al. 2016). Child marriages and early births are a source of enormous health risks to girls and their offspring. It robs them of the bright, healthy and economically sound future by exposing them too early to repeated births at short intervals (Raj et al. 2009). A combination of these create fertile ground for obstetric complications that lead to maternal mortality which is highest among young women in developing countries (Patton et al. 2009). The HIV prevalence is characteristically high among young women than young men; more so among young married women than their sexually active unmarried colleagues (Freeman et al. 2006), since, as evidence has shown, they marry older men with whom they have limited negotiating power for protected sexual intercourse even when they suspect that their husband might be infected (Bracher, Santow, and Watkins 2003; Foreman et al. 2018; Koski, Clark, and Nandi 2017). Women's age at first marriage and first birth are strong candidates for explaining changes in CFS. However, it is worth noting that simplistically confining the determinants of CFS to two variables undermines the importance of environmental factors that contribute to fertility change. The interactions between timing of reproductive events on the one hand with other factors such as education, contraception use, household wealth and place of residence on the other, provide a complex network of interrelations that influence change in reproductive behaviors of women that affect the number of children they bear in their lives. To ensure young women have a choice regarding the timing of their reproductive events, national guidelines that protect the lives of young girls need strengthening to ensure women get married and start childbearing at an age when they are well developed to face the social and economic challenges of life that come with motherhood.

Author Contribution: N.M., T.N.M., conceived and designed the study. N.M. contributed to data procurement. N.M. and T.N.M. designed statistical analysis, performed data analysis and wrote the initial draft manuscript. N.M., T.N.M., J.L.W and X.C.Q. read, reviewed, revised and approved content before submission.

Role of the funding source: The study received no external funding.

Conflict of Interests: The authors declare no conflicts of interest.

Data sharing: Data used in this article are available to bona fide researchers on request from the DHS program: https://dhsprogram.com/data/dataset admin/ 


\section{References:}

Ariho, Paulino, and Allen Kabagenyi. 2020. "Age at First Marriage, Age at First Sex, Family Size Preferences, Contraception and Change in Fertility among Women in Uganda: Analysis of the 2006-2016 Period." BMC women's health 20(1): 8.

Behrman, Jere R., and Shireen J. Jejeebhoy. 1996. “Women's Education, Autonomy, and Reproductive Behaviour: Experience from Developing Countries." Population and Development Review 22(4): 789.

Biddlecom A, Gregory R, Lloyd CB, and Mensch Bs. 2007. "Premarital Sex and Schooling Transitions in Four Sub-Saharan African Countries." Poverty, Gender, and Youth Working Paper No. 5 2008(5): 337-50.

Bongaarts, John. 2017. "Africa's Unique Fertility Transition." Population and Development Review 43: 39-58.

Bongaarts, John, and Ann K. Blanc. 2015. "Estimating the Current Mean Age of Mothers at the Birth of Their First Child from Household Surveys." Population Health Metrics 13(1): 1-6. http://dx.doi.org/10.1186/s12963-015-0058-9.

Bongaarts, John, Barbara S. Mensch, and Ann K. Blanc. 2017. "Trends in the Age at Reproductive Transitions in the Developing World: The Role of Education." Population Studies 71(2): 139-54. Bourgeois-pichat, Jean. 2012. "Social and Biological Determinants of Human Fertility in Nonindustrial Societies Author ( s ): Jean Bourgeois-Pichat Reviewed Work ( s ): Source: Proceedings of the American Philosophical Society, Vol .111, No . 3, Population Published by: American." Proceeding of the American Philosophical Society 111(3): 160-63.

Bracher, Michael, Gigi Santow, and Susan Cotts Watkins. 2003. “'Moving' and Marrying: Modeling HIV Infection among Newly-Weds in Malawi." Demographic Research 9(SUPPL. 1): 207-46.

C.J.Mann. 2003. “Observational Research Methods. Research Design II : Cohort. Cross Sectional, and Case-Control Studies." Emergency Medicine Journal: 54-61.

Carlson, Melissa D.A., and R. Sean Morrison. 2009. “Study Design, Precision, and Validity in Observational Studies." Journal of Palliative Medicine 12(1): 77-82.

Caroline, Kabiru, and Ezeh Alex. 2009. "Factors Associated with Sexual Abstinence among Adolescents in Four Sub-Saharan African Countries." African Journal of Reproductive Health 11(3).

Central Statistical Office, Ministry of Health, Tropical diseases Research Centre, University of Zambia. 2009. Zambia Demographic and Health Survey 2007.

Central Statistical Office, Ministry of Health, University of Zambia Teaching Hospital, Tropical diseases Research Centre, University of Zambia, The DHS Program. 2015. Zambia Demographic and Health Survey 2013-14.

Central Statistical Office et al. 2015. Zambia Demographic and Health Survey 2013-14.

Central Statistical Office (CSO);, Central Board of Health [Zambia];, and ORC Macro. 2003. Zambia Demographic and Health Survey 2001-2002. Calverton.

Central Statistical Office (CSO) et al. 2009. Demographic and Health Survey Zambia Demographic and Health Survey 2007. https://dhsprogram.com/pubs/pdf/FR211/FR211[revised-05-12-2009].pdf.

Central Statistical Office (CSO) [Zambia], Ministry of Health (MOH) [Zambia], and ICF International. 2014. Zambia Demographic and Health Survey Zambia Demographic and Health Survey 2013-14. Maryland. https://www.dhsprogram.com/pubs/pdf/FR304/FR304.pdf. 
Central Statistical Office Zambia (CSO). 2010. “2010 Census of Population and Housing Batangas.” Central Statistical Office: 1-120.

Central Statistical Office, Ministry of Health Zambia, and Macro International Inc. 1997. Zambia Demographic and Health Survey 1996.

Channon, Melanie Dawn, and Sarah Harper. 2019. "Educational Differentials in the Realisation of Fertility Intentions: Is Sub-Saharan Africa Different?" ed. Mellissa H. Withers. PLOS ONE 14(7): e0219736. http://dx.plos.org/10.1371/journal.pone.0219736 (April 22, 2020).

Clark, Shelley, Caroline Kabiru, and Rohini Mathur. 2010. "Relationship Transitions among Youth in Urban Kenya." Journal of Marriage and Family 72(1): 73-88.

Clark, Shelley, and Rohini Mathur. 2012. "Dating, Sex, and Schooling in Urban Kenya." Studies in Family Planning 43(3): 161-74.

Corno, Lucia, Nicole Hildebrandt, and Alessandra Voena. 2017. “AGE OF MARRIAGE, WEATHER SHOCKS, AND THE DIRECTION OF MARRIAGE PAYMENTS." NATIONAL BUREAU OF ECONOMIC RESEARCH NBER Worki. http://www.nber.org/papers/w23604.

Delprato, Marcos, Kwame Akyeampong, Ricardo Sabates, and Jimena Hernandez-Fernandez. 2015. "On the Impact of Early Marriage on Schooling Outcomes in Sub-Saharan Africa and South West Asia." International Journal of Educational Development 44: 42-55. http://dx.doi.org/10.1016/j.jijedudev.2015.06.001.

Erens, Bob et al. 2014. "Methodology of the Third British National Survey of Sexual Attitudes and Lifestyles (Natsal-3)." Sexually Transmitted Infections 90(2): 84-89.

Field, Erica, and Attila Ambrus. 2008. "Early Marriage, Age of Menarche, and Female Schooling Attainment in Bangladesh." Journal of Political Economy 116(5): 881-91.

Foreman, Kyle J. et al. 2018. "Forecasting Life Expectancy, Years of Life Lost, and All-Cause and Cause-Specific Mortality for 250 Causes of Death: Reference and Alternative Scenarios for 2016-40 for 195 Countries and Territories." The Lancet 392(10159): 2052-90. http://dx.doi.org/10.1016/S0140-6736(18)31694-5.

Freeman, Esther E. et al. 2006. "Herpes Simplex Virus 2 Infection Increases HIV Acquisition in Men and Women: Systematic Review and Meta-Analysis of Longitudinal Studies." Aids 20(1): 7383.

Gangadharan, Lata, and Pushkar Maitra. 2003. "The Effect of Education on the Timing of Marriage and First Birth in Pakistan." Journal of Quantitative Economics 1(1): 114-33.

Garenne, M. 2004. "Age at Marriage and Modernisation in Sub-Saharan Africa." Southern African Journal of Demography 9(2): 59-79. https://core.ac.uk/download/pdf/39843831.pdf.

Gerland, Patrick, Ann Biddlecom, and Vladimíra Kantorová. 2017. "Patterns of Fertility Decline and the Impact of Alternative Scenarios of Future Fertility Change in Sub-Saharan Africa." Population and Development Review 43: 21-38.

Gilles Pison. 2017. "The Population of the World (2017)." Population and Societies (547).

- - - "Why African Families Are Larger than Those of Other Continents." https://theconversation.com/why-african-families-are-larger-than-those-of-other-continents84611 (April 22, 2020).

Glick, Peter, Christopher Handy, and David E. Sahn. 2015. "Schooling, Marriage, and Age at First Birth in Madagascar." Population Studies 69(2): 219-36. http://dx.doi.org/10.1080/00324728.2015.1053513. 
Grant, Monica J, and Kelly K Hallman. 2008. "Pregnancy-Related School Dropout and Prior School Performance in KwaZulu-Natal, South Africa." Studies in Family Planning 39(4): 369-82.

Hertrich, Véronique. 2017. “Trends in Age at Marriage and the Onset of Fertility Transition in SubSaharan Africa." Population and Development Review 43: 112-37.

Jayaraman, Anuja, Tesfayi Gebreselassie, and S. Chandrasekhar. 2009. "Effect of Conflict on Age at Marriage and Age at First Birth in Rwanda." Population Research and Policy Review 28(5): 55167.

Koski, Alissa, Shelley Clark, and Arijit Nandi. 2017. "Has Child Marriage Declined in Sub-Saharan Africa? An Analysis of Trends in 31 Countries." Population and Development Review 43(1): 7-29. Lesthaeghe, R, G Kaufmann, D Meekers, and Vrije Universiteit. 1989. "The Nuptiality Regimes in Sub-Saharan Africa." In Reproduction and Social Organization in Sub-Saharan Africa, ed. Ron Lesthaeghe. Berkelry/ Los Angeles: University of California Press.

Lloyd, Cynthia B. 2010. "The Role of Schools in Promoting Sexual and Reproductive Health among Adolescents in Developing Countries." In Social Determinants of Sexual and Reproduc- Tive Health: Informing Future Research and Programme Implementation, ed. Shawn Malarcher. , 113-31. Lloyd, Cynthia B., Jere R. Behrman, Nelly P. Stromquist, and Barney Cohen. 2005. The Changing Transitions to Adulthood in Developing Countries: Selected Studies The Changing Transitions to Adulthood in Developing Countries: Selected Studies.

MacQuarrie, Kerry LD. 2016. "Marriage and Fertility Dynamics: The Inlluence of Marriage Age on the Tining of First Birth and Birth Spacing. DHS Analytical Studies 56." (August): 140. https://dhsprogram.com/pubs/pdf/AS56/AS56.pdf\%0Ahttp://dhsprogram.com/pubs/pdf/AS56 /AS56.pdf.

Manda, Samuel, and Renate Meyer. 2018. "Age at First Marriage in Malawi: A Bayesian Multilevel Analysis Using a Discrete Time-to- Event Model." Journal of the Royal Statistical Society. Series A (Statistics in Society) 168(2): 439-55.

Marini, Margaret Mooney. 1981. "Effects of the Timing of Marriage and First Birth on Fertility." Journal of Marriage and the Family 43(1): 7.

Maswikwa, Belinda, Linda Richter, Jay Kaufman, and Arijit Nandi. 2015. “Minimum Marriage Age Laws and the Prevalence of Child Marriage and Adolescent Birth: Evidence from Sub-Saharan Africa." International Perspectives on Sexual and Reproductive Health 41(2): 58-68.

Mensch, Barbara S., Monica J. Grant, and Ann K. Blanc. 2006. “The Changing Context of Sexual Initiation in Sub-Saharan Africa." Population and Development Review 32(4): 699-727.

Mensch, Barbara S., Susheela Singh, and John B. Casterline. 2006. "Trends in the Timing of First Marriage among Men and Women in the Developing World." The Changing Transitions to Adulthood in Developing Countries: Selected Studies (202): 118-71.

Muhoza, Dieudonné Ndaruhuye, Annelet Broekhuis, and Pieter Hooimeijer. 2014. “Variations in Desired Family Size and Excess Fertility in East Africa." International Journal of Population Research 2014: 1-11.

Ortega, José Antonio. 2014. "A Characterization of World Union Patterns at the National and Regional Level." Population Research and Policy Review 33(2): 161-88.

Patton, George C. et al. 2009. “Global Patterns of Mortality in Young People: A Systematic Analysis of Population Health Data.” The Lancet 374(9693): 881-92.

Population Reports. 1979. VII Age at Marriage and Fertility. Baltimore. 
Poulin, Michelle. 2007. "Sex, Money, and Premarital Partnerships in Southern Malawi." Social Science and Medicine 65(11): 2383-93.

Quisumbing, Agnes R., and John A. Maluccio. 2003. "Resources at Marriage and Intrahousehold Allocation: Evidence from Bangladesh, Ethiopia, Indonesia, and South Africa." Oxford Bulletin of Economics and Statistics 65(3): 283-327.

Raj, Anita, Niranjan Saggurti, Donta Balaiah, and Jay G Silverman. 2009. "Prevalence of Child Marriage and Its Impact on the Fertility and Fertility Control Behaviors of Young Women in India." Lancet 373(9678): 1-20.

https://www.ncbi.nlm.nih.gov/pmc/articles/PMC2759702/pdf/nihms120358.pdf.

Sedgwick, Philip. 2014. “Cross Sectional Studies: Advantages and Disadvantages." BMJ (Online) 348(March 2014): 8-10.

Setia, Maninder Singh. 2016. "Methodology Series Module 3: Cross-Sectional Studies Maninder." Indian Journal of Dermatology 61(3): 261-64. http://www.e-ijd.org/text.asp?2016/61/3/261/182410.

Shapiro, David, and Tesfayi Gebreselassie. 2014. "Marriage in Sub-Saharan Africa: Trends,

Determinants, and Consequences." Population Research and Policy Review 33(2): 229-55.

StataCorp LLC. 2016. "Stata Version 14.2." College Station. www.stata.com (March 17, 2016).

“The DHS Program - Available Datasets." https://dhsprogram.com/data/available-datasets.cfm (April 24, 2020).

United Nation Department of Economic and Social Affairs. 2017. Population Facts: Household Size and Composition around the World.

United Nations Children's Fund (UNICEF). 2014. Generation 2030 | Africa. New York. www.unicef.org/publications.

- - -. “Africa Will Be Home to 2 in 5 Children by 2050: UNICEF Report I Press Centre I UNICEF." https://www.unicef.org/media/media_74754.html (April 22, 2020).

University of Zambia (UNZA), Central Statistical Office (CSO), and Macro International Inc. 1993. Zambia Demographic and Health Survey 1992. Macro International Inc. https://dhsprogram.com/pubs/pdf/FR42/FR42.pdf.

Walle, Etienne van de. 1993. "Recent Trends in Marriage Ages." In Demographic Change in SubSaharan Africa, eds. K.A. Foote, K.H. Hill, and L.G. Martin. The National Academies Press. https://www.nap.edu/read/2207/chapter/5 (April 23, 2020).

Wang, Haidong et al. 2016. "Estimates of Global, Regional, and National Incidence, Prevalence, and Mortality of HIV, 1980-2015: The Global Burden of Disease Study 2015." The Lancet HIV 3(8): e361-87. http://linkinghub.elsevier.com/retrieve/pii/S235230181630087X.

Westoff, C. F. 1992. 169 World Bank Technical Paper Age at Marriage, Age at First Birth, and Fertility in Africa.

Zambia Statistical Agency (ZSA), Ministry of Health [Zambia], University Teaching Hospital Virology Laboratory, and The DHS Program [ICF]. 2019. Zambia Demographic and Health Survey 2018.

(C) 2020 by the authors. Submitted for possible open access publication under the terms and conditions of the Creative Commons Attribution (CC BY) license (http://creativecommons.org/licenses/by/4.0/). 